\title{
FREEZING OF GAIT IN PARKINSON'S DISEASE: IMPACT ON FALLS RISK, WALKING AIDS UTILIZATION, AND ASSISTANCE-SEEKING BEHAVIOUR
}

\author{
Ehab Georgy
}

\section{Senior Physiotherapist, Hampshire Community Health Care, United Kingdom}

Freezing of Gait (FOG) is one of the most disturbing symptoms in advanced stage of Parkinson's disease (PD) that is strongly associated with recurrent falls and reduced functional independence. The purpose of the study was to determine the impact of FOG on mobility in terms of risk of falls, walking aids utilization and assistance-seeking behaviour by comparing freezers (FRs) and nonfreezers (NFRs). Clinical and demographic data, including disease duration, stage and characteristics, cognition, medication, history of falls, walking aids utilization, and assistanceseeking behaviour was collected from 102 subjects with PD from three medical centres in Belgium, Israel, and UK. Association between FOG and other disease characteristics, medication, falls, walking aids, and need for carers' assistance was investigated. Comparing FRs and NFRs showed significant difference in history of previous falls, walking aids utilization, and need for carers' assistance. More than half of the FRs reported previous fall and a need for walking aids for mobility compared to $20 \%$ in NFRs group. A vicious cycle exists among subjects with PD who experience FOG. Gait freezing induces increased risk and frequency of falls as well as increased fear of falling, which in turn increases the tendency towards higher reliance on carers' assistance and more utilization of walking aids.

KEYWORDS: Parkinson's disease, gait freezing, falls, walking aids, assistance.

\section{INTRODUCTION}

Freezing of gait (FOG) is a frequent phenomenon in subjects with Parkinson's disease (PD), with prevalence rates ranging from $7 \%$ in the early stages of PD to about $60 \%$ in the more advanced stages (Bartels, Balash, Gurevich, Schaafsma, Hausdorff, \& Giladi, 2003; Giladi et al., 2001a; Giladi et al., 2001b; Lamberti et al., 1997). Giladi et al. (2001a) stated that $53 \%$ of those with disease duration of more than five years develop FOG. Typically, FOG is a transient halt of gait, lasting <1 min, during which the subject complains that his feet are suddenly "glued to the floor" (Schaafsma, Balash, Gurevich, Bartels, Hausdorff, \& Giladi, 2003). During a typical FOG episode, such feeling exists for a few seconds (Giladi et al., 2001a). When starting to walk, subjects with PD may experience FOG as a sudden inability to initiate walking or a temporary difficulty in continuation of walking (Bartels et al., 2003). Other situations that elicit FOG include turning hesitation, approaching narrow spaces such as doorways, reaching destination, or even spontaneously whilst walking in open space (Schaafsma et al., 2003). It has been suggested that FOG should be added to the list of cardinal symptoms of PD (Fahn, 1995; Giladi et al., 2001b), in part because of its important independent effects on function and quality of life in PD (Hausdorff, Schaafsma, Balash, Bartels, Gurevich \& Giladi, 2003), and also because its underlying pathophysiologic mechanisms seem to be different from those of other features of PD (Bartels et al., 2003; Hausdorff et al., 2003).

Gait disturbances in general, and FOG more specifically, may partly develop as a result of both the complex effect of the progression of the disease in conjunction with long term side effects of antiparkinsonian medication (Giladi et al., 2001a; Giladi et al., 2001b). FOG is rarely the presenting symptom of PD (Lamberti et al., 1997); however, at the advanced stages of the disease, FOG is a very disabling symptom, lasting seconds to minutes, frequently 
associated with falls and injuries, and may as well become the most disabling symptom which forces the patient to stay at home or use a wheelchair (Giladi et al., 2001a). FOG is associated with increased risk of falls and fractures, hospitalization, loss of independence, impaired health-related quality of life, and even higher risk of mortality (Bloem, Hausdorff, Visser, \& Giladi, 2004; Cubo, Leurgans \& Goetz, 2004; Giladi et al., 2001a; Gray \& Hildebrand, 2000; Hely, Morris, Traficante, Reid, O'Sullivan \& Williamson, 1999). Gait disturbance, reduced mobility, falls risk and social isolation are the major contributors that might negatively influence the patients' physical and mental health, social interaction, and quality of life (Bloem et al., 2004; Davis, Lyons, \& Pahwa, 2006). The fear of additional falls due to FOG leads to restriction of activities and reduced mobility, which in turn can lead to a higher likelihood of osteoporosis and accordingly higher risk of fractures (Bloem et al., 2004; Davis et al., 2006). Health care systems are always striving to reduce hospital admission due to its anticipated devastating impact and negative effects on patients' health as well as its economical and financial burden. Previous falls history or high risk of falls are among the leading reasons for hospital admission; therefore, studies investigating causes and possible predictors of falls in different patients' groups are significantly important in order to design rehabilitation approaches and interventions that can tackle and modify such precipitating risk factors. Based on the reviewed literature that suggests a link between FOG and falls risk, this study provides further exploration of this aspect by investigating the association between FOG and risk of falls, walking confidence and level of independence. The current study aims to investigate the impact of FOG on mobility in terms of falls risk, walking aids utilization, and assistance-seeking behaviour while mobilising in subjects with PD by comparing freezers (FRs) and non-freezers (NFRs). Further analysis of the association between gait freezing and disease stage, characteristics and medication is also reported.

\section{SUBJECTS AND METHODS}

This study build its basis on a larger study (Nieuwboer et al., 2009), which aimed at investigating and establishing the validity and reliability of the New Freezing of Gait Questionnaire (NFOG-Q); data from this bigger study was used as basis of the current analysis.

\section{Study population}

Participants were one hundred and two subjects from three different medical centres: Tel-Aviv Sourasky Medical Centre, Israel (n = 23); University Hospital Leuven, Belgium $(\mathrm{n}=40)$; and Northumbria University, United Kingdom $(n=39)$. Data collection was completed by February 2007 with all required demographic and clinical data being collected from all participants from the three medical centres and gathered in Belgium for analysis. All patients attending neurology outpatient clinic and fulfilling the inclusion criteria were asked to participate in the study over a 9month period. Eligible participants were identified by a consultant neurologist during the hospital visit according to the following inclusion criteria: diagnosis of PD using the Brain Bank criteria (Hughes, Daniel, Kilford, \& Lees, 1992), a Mini Mental State Exam (MMSE) score of at least 24 and were clinically non-demented. Subjects were taking their regular medication during testing.

\section{Design and procedure}

The study adopted a prospective crosssectional correlational design. Demographic and clinical data was collected for all subjects, including years since the onset of disease, previous brain surgery, cognition (MMSE), and the Hoehn \& Yahr disease stage scale (H\&Y) (Hoehn \& Yahr, 1967). Subjectreported history of falls, in terms of number and type of previous falls within the last six months, as well as subject-reported walking aids utilization were recorded. Assistanceseeking behaviour, i.e. the need for carers help (spouse, relative or other), was also reported by asking the subjects to identify the range of functional activities they might need help with. Disease characteristics were explored by completing part three of the 
Unified Parkinson's Disease Rating Scale (UPDRS-III), which investigates the impact of PD on the motor function, in addition to question 14 (Q-14) of part two of the scale (UPDRS-II), which investigates the frequency of occurrence of FOG and its impact on walking and falls (Fahn \& Elton, 1987).

The NFOG-Q, a valid and reliable tool for measuring FOG (Nieuwboer et al., 2009), was used to distinguish between FRs and NFRs. Part I of the questionnaire detected the presence of FOG using a dichotomous item in which individuals were classified as a FRs or a NFRs if they had experienced FOGepisodes during the past month. Part II mainly investigates the severity of FOG in terms of the duration and frequency of the episodes in its most common manifestation, i.e. during turning and initiation of gait (items 2-6). While Part III is concerned with the impact of FOG on daily life activities and function (items 7-9). To enhance the description of FOG, all participants watched a video to clarify different types and duration of FOG episodes; this 70-second video segment contained one general example of FOG in a doorway, then 3 more examples were shown: two of turning-FOG (11 seconds and 1 second) and one of initiation-FOG (5 seconds). Each subject was allowed to watch the video for a maximum of two times before completing the questionnaire. Patients were asked to complete the NFOG-Q in general; i.e. not distinguishing between on and off states; the "off" state is when the effect of medication starts to wear off and the symptoms of PD start to worsen before the next dose of medication is administered. This is likely to affect the severity of FOG and its impact on gait and function.

Antiparkinsonian medication was recorded in a separate medication spreadsheet. To investigate the relationship between FOG and different antiparkinsonian medication, the daily dopamine dose equivalent was calculated so that a $100 \mathrm{mg}$ daily dose of standard Levodopa was equivalent to the following doses of other medications: $133 \mathrm{mg}$ of controlled-release Levodopa; $75 \mathrm{mg}$ of Levodopa plus Entacapone; $1 \mathrm{mg}$ of
Pergolide, Pramipexole, or Cabergoline; $5 \mathrm{mg}$ of Ropinirole; and $10 \mathrm{mg}$ of Bromocriptine (Deuschl, Schade-Brittinger, Krack et al., 2006).

All subjects provided informed consent according to the Declaration of Helsinki and approved by the Ethics Committee University Hospital Leuven, Tel Aviv Sourasky Medical Centre Ethics Committee and Sunderland Local Research Ethics Committee. The NFOG-Q was written in English and translated to Dutch and Hebrew. Data collection procedures were standardized and harmonized across centres by means of a detailed data collection booklet summarizing data collection techniques and procedures as well as all spreadsheets and data collection forms and templates to be used.

\section{Statistical analysis}

Distinguishing FRs and NFRs. Kappa statistic for agreement was calculated between NFOG-Q and Q-14 scores to ensure accurate identification of all FRs within the participants and to investigate the ability of the NFOG-Q to distinguish between FRs and NFRs.

Comparison between FRs and NFRs. Chi-Square test was used to investigate differences in falls risk, walking aids utilization, and assistance-seeking behaviour between FRs and NFRs. Further analysis was done to investigate possible aggravating factors by exploring the differences between FRs and NFRs in terms of age, cognitive function (MMSE) and disease duration using unpaired t-test. Mann-Whitney $U$ test was used to investigate the difference in disease stage by comparing the H\&Y scores between the two subgroups. To investigate the difference in disease characteristics between FRs and NFRs, a single score for the UPDRS items including multiple body parts was generated based on the worst function in case of asymmetry between right and left. The total scores on the UPDRS were compared between FRs and NFRs using unpaired t-test.

Correlation between FOG and other disease characteristics. Further elaboration and analysis of the data were done to explore the association between gait freezing and 
other significant disease characteristics by analysing the collected data from all participants $(n=102)$ regardless of the FRs/NFRs status. To investigate the relationship between FOG and disease characteristics, all participants' NFOG-Q scores were correlated with the UPDRS-III scores using Spearman's correlation coefficient. In addition, the total NFOG-Q scores were correlated with question 29 (Q29) of the UPDRS-III, which specifically mobility. The total NFOG-Q scores were also correlated to the H\&Y scores and the daily dopamine dose equivalent using Spearman's coefficient. A p-value of less than 0.05 (twotailed) was considered statistically significant. Statistical analysis was performed using SPSS for Windows (Version 11.5).

\section{RESULTS}

Subjects' characteristics

Table 1.

Subjects' characteristics are shown in investigates the gait disturbance and the need for assistance while walking for further indepth analysis of the impact of FOG on

Table 1

Subjects' characteristics

\begin{tabular}{|c|c|c|c|c|c|c|c|c|c|}
\hline Gender & $\begin{array}{l}\text { Age } \\
\text { years }\end{array}$ & $\begin{array}{c}\text { DD } \\
\text { years }\end{array}$ & MMSE & $\begin{array}{c}\text { H\&Y } \\
\%\end{array}$ & UPDRS & Falls & $\begin{array}{l}\text { Walking } \\
\text { aids }\end{array}$ & Assistance & $\begin{array}{l}\text { Levodopa } \\
\text { mg }\end{array}$ \\
\hline $\begin{array}{c}M=68 \\
F=34\end{array}$ & $\begin{array}{l}68.5 \\
\pm 8.4\end{array}$ & $\begin{array}{c}9.6 \\
\pm 6.4\end{array}$ & $\begin{array}{l}28.1 \\
\pm 1.9\end{array}$ & $\begin{array}{c}7.5 \text { (I), } 16 \text { (II) } \\
65.5 \text { (III), } 16 \text { (IV) }\end{array}$ & $\begin{array}{c}30.4 \\
\pm 13.6\end{array}$ & $42 \%$ & $45 \%$ & $68 \%$ & $578.5 \pm 563$ \\
\hline
\end{tabular}

Figures represent mean values $\pm S D$, except for gender, falls, walking aids and assistance. $M=$ male and $F=$ female, $D D=$ disease duration, MMSE = Mini Mental State Exam, $H \& Y=$ Hoehn and Yahr stage (I-IV), UPDRS = Unified Parkinson Disease Rating Scale, \% Falls = percentage of patient reporting a fall over the last 6 months.

One hundred and two subjects participated in the study (68 male, 34 female), with average age of 68.5 years and mean disease duration of 9.6 years. The mean score on the MMSE was $28.1( \pm 1.9)$. Ten subjects $(9.8 \%)$ had undergone deep brain stimulation. Ninety percent of the patients received an average Levodopa dose of $578.5 \mathrm{mg}$ /day. Seven and half percent of the subjects were in stage I of the disease according to $\mathrm{H} \& \mathrm{Y}$ clinical staging, $16 \%$ were in stage II, $65.5 \%$ were in stage III and $16 \%$ were in stage IV. The mean UPDRS-III score was 30.4. Fortyfive percent of the subjects reported using walking aids for mobility, including walking sticks, walkers, rollators, and electric scooters. Forty-two percent reported previous history of falls during the previous 6 months, ranging from one to 360 falls. Sixty-eight percent of the subjects needed various forms of assistance. Assistance was provided by spouse in $86 \%$ of the cases; other carers included other family members $(4 \%)$, distant relatives $(4 \%)$, or professional caregivers (6\%). Subjects reported needing assistance with washing and dressing (58\%), gait (33\%), fine motor activities $(21 \%)$, rising from bed $(15 \%)$, transfer activities (7\%), domestic help $(6 \%)$, and turning in bed $(5 \%)$.

\section{Distinguishing FRs and NFRs}

In order to accurately identify FRs among all participants and to examine the ability of the NFOG-Q to distinguish between FRs and NFRs, a 2x2 table for agreement was constructed between NFOG-Q and Q-14 (UPDRS-II) scores. Kappa statistic for agreement was calculated at 0.65 , showing a moderate agreement. Q-14 data was not available for one patient. Table 3 summarizes the relationship between the Q-14 and the NFOG-Q mean scores. 
Table 2

Agreement between NFOG-Q and Q-14 scores

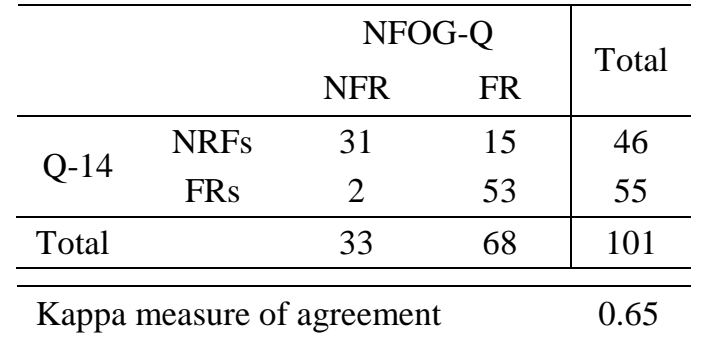

\section{Comparing FRs and NFRs}

Comparing FRs and NFRs showed no significant differences regarding age $(\mathrm{p}=$ 0.853) or MMSE ( $p=0.762)$. Comparing disease profiles between FRs and NFRs (Table 4) showed that FRs had significantly longer disease duration (10.9 \pm 6.1 years versus $8 \pm 6.2$ years, $p=0.0001)$, more severe $\mathrm{H} \& \mathrm{Y}$ stages $($ median $=3[2 ; 4]$ versus $2[0$; 3 ], $\mathrm{p}<0.0001$ ), and higher UPDRS-III scores $(31.9 \pm 15.7$ versus $22.7 \pm 11.7, \mathrm{p}=0.003)$.

\section{Table 3}

Descriptive summary of the relationship between the Q-14 and NFOG-Q mean scores

\begin{tabular}{ccc}
\hline $\begin{array}{c}\text { Q-14 } \\
\text { score }\end{array}$ & $\%$ & $\begin{array}{c}\text { Mean } \\
\text { NFOG-Q }\end{array}$ \\
\hline 0 & 45 & 5.6 \\
1 & 17 & 16 \\
2 & 18 & 18.7 \\
3 & 15 & 21.5 \\
4 & 5 & 25.4 \\
\hline
\end{tabular}

Chi square was used to compare FRs and NFRs in terms of falls history, walking aids utilization, and need for assistance (Table 5). There were significant differences in the use of walking aids $(\mathrm{p}=0.0004)$, previous history of falls $(\mathrm{p}=0.006)$, and need for assistance ( $\mathrm{p}$ $=0.002$ ). FRs used more walking aids, tended to fall more, and seemed to be in more need for assistance by their carers.

\section{Table 4}

Comparison between FRs and NFRs for age, cognitive function (MMSE), disease duration, characteristics (UPDRS) and stage (H\&Y)

\begin{tabular}{llll}
\hline & Freezers & Non-freezers & P value \\
\hline Age & $68.4 \pm 8.5$ & $68.8 \pm 8.2$ & 0.853 \\
MMSE & $28 \pm 1.9$ & $28.1 \pm 1.8$ & 0.762 \\
Duration & $10.9 \pm 6.1$ & $8 \pm 6.2$ & $0.0001^{* *}$ \\
UPDRS & $31.9 \pm 15.7$ & $22.7 \pm 11.7$ & $0.003^{* *}$ \\
H\&Y & $3\{2-4\}$ & $2\{0-3\}$ & $0.0001^{* *}$ \\
\hline
\end{tabular}

Figures represent mean values \pm standard deviation, except for the disease stage, where it represents median and range, ${ }^{* *}$ Significant defference.

Comparing assistance-seeking behaviour between FRs and NFRs revealed that only three NFRs sought their carers' help for mobility. The majority of activities that required carers' assistance were washing and dressing, bed mobility, and other domestic help. On the other hand, FRs sought help more often. Eighteen FRs reported that they required assistance while mobilising, and 15
FRs stated that they needed their carers to help them with various transfer activities including rising from chair or bed, car transfers, or getting in and out of bath. Additionally, assistance for washing and dressing were fairly prevalent in the FRs subgroup. A larger proportion of FRs (52\%) reported a fall over the past 6 months than NFRs $(21 \%)(p=0.003)$. 
Table 5

Comparison between FRs and NFRs for falls, walking aids utilization and need for assistance

\begin{tabular}{|c|c|c|c|c|c|c|}
\hline & & FRs & NFRs & Total & $X^{2}$ & $P$ \\
\hline \multirow{3}{*}{ Previous Falls } & No & 33 & 26 & 59 & \multirow{3}{*}{7.6} & \multirow{3}{*}{.0006} \\
\hline & Yes & 36 & 7 & 43 & & \\
\hline & Total & 69 & 33 & 102 & & \\
\hline \multirow{3}{*}{ Walking aids } & No & 29 & 27 & 56 & \multirow{3}{*}{12.7} & \multirow{3}{*}{.0004} \\
\hline & Yes & 40 & 6 & 46 & & \\
\hline & Total & 69 & 33 & 102 & & \\
\hline \multirow{3}{*}{ Assistance } & No & 15 & 18 & 33 & \multirow{3}{*}{9.5} & \multirow{3}{*}{.0002} \\
\hline & Yes & 54 & 15 & 69 & & \\
\hline & Total & 69 & 33 & 102 & & \\
\hline
\end{tabular}

$X^{2}=$ Chi Square Statistic

More than half of the FRs $(58 \%)$ needed to use different walking aids for mobility, compared to $18 \%$ only of the NFRs ( $\mathrm{p}=$ 0.004). Similarly, more than two thirds of the FRs $(78 \%)$ needed carer assistance, while less than half of the NFRs required such assistance $(p=0.002)$. Within the FRs group, significant correlations were found between NFOG-Q scores and $H \& Y$ stage $(R=0.3, p=0.03)$ and falling $(\mathrm{R}=0.35, \mathrm{p}=0.003)$.

\section{Correlation between FOG and other disease characteristics}

Spearman correlation coefficient showed weak correlation between NFOG-Q and UPDRS-III scores $(\mathrm{R}=0.24, \mathrm{p}=0.018)$, moderate correlation between NFOG-Q and $\mathrm{H} \& \mathrm{Y}$ scores $(\mathrm{R}=0.6, \mathrm{p}=0.0002)$, and moderate correlation with the daily dopamine dose equivalent $(\mathrm{R}=0.5, \mathrm{p}=0.0001)$. Spearman's coefficient also showed moderate correlation between NFOG-Q total scores and $\mathrm{Q}-29$ of the UPDRS-III $(\mathrm{R}=0.6, \mathrm{p}=0.0002)$.

\section{DISCUSSION}

The freezing phenomenon has been observed in subjects with PD for more than 120 years, but its pathophysiology and clinical course remain poorly understood (Giladi et al., 2001b). FOG is a frequent feature associated with PD with significant effect on patient's mobility and quality of life (Giladi, Shabtai, Rozenberg, \& Shabtai, 2001c). The episodic nature of this symptom, the effect of visual and auditory stimuli, and mood influence make FOG a complex symptom to study (Giladi et al., 2001b). This article compared FRs and NFRs to investigate the impact of FOG on mobility in terms of falls risk, walking aids utilization, and assistance-seeking behaviour while mobilising, as well as to explore the relationship between FOG and other PD characteristics.

In the current study, the NFOG-Q was effectively used to distinguish FRs and NFRs. The moderate agreement $($ Kappa $=0.65)$ between NFOG-Q and Q-14 of UPDRS-II (frequency of FOG and its impact on walking and falls) suggests that the two scales were measuring a similar construct, but it was not so high as to suggest that the two scales were necessarily measuring the same dimensions of FOG. Question 14 of the UPDRS-II is mainly concerned with the impact of falls and FOG on the daily life activities, while NFOG-Q was constructed to assess the different aspects of FOG including presence, severity in terms of duration and frequency, and finally the impact on function and activities. The moderate correlation between the two measures reflects the ability of NFOG-Q to distinguish between FRs and NFRs.

When comparing FRs and NFRs, there was no significant difference regarding age ( $p$ $=0.853)$ and MMSE $(p=0.762)$. It was previously suggested that FRs are, in general, more motor impaired than NFRs as a result of 
specific attention deficit and that such frontal attention deficits may form the basis for FOG in PD (Camicioli, Oken, Sexton, Kaye \& Nutt, 1998). Furthermore, strong correlation was found between stress, anxiety, depression, and cognitive impairment, and it was suggested that those factors might set the stage for and increase the likelihood of FOG (Giladi \& Hausdorff, 2006). However, the current study showed no significant difference in the MMSE scores between FRs and NFRs; possibly, due to the fact that subjects with MMSE scores of less than 23 were excluded from the study. In this study context, comparison of MMSE between FRs and NFRs should not be used to explain the impact of mental condition on the development of FOG. Conversely, comparing FRs and NFRs revealed significant differences in disease duration, $H \& Y$ stage, UPDRS-III score, and daily Dopamine dose, with the FRs having longer disease duration, higher H\&Y stages, higher UPDRS-III scores, and higher medication doses, which again stresses the role of disease duration, disease progression and Levodopa treatment as significant contributing factors for the presence of FOG.

Comparing history of previous falls, walking aids utilization, and need for carers' assistance between FRs and NFRs showed significant difference between the two groups. FRs tended to use walking aids more than NFRs, yet they were still more susceptible to falls than NFRs. More than half of the FRs reported between one and 360 falls within the last six months compared to only $20 \%$ of NFRs reporting falls. Falls secondary to gait disturbances and FOG in subjects with PD might be attributed to less rhythmic accelerations at the pelvis in the vertical and anteroposterior planes, which creates an inability to control displacements of the torso when walking and might impose higher predisposition to falls in this population (Latt, Menz, Fung, \& Lord, 2009). Similarly, more than half of the FRs stated that they needed to use different walking aids for mobility compared to $18 \%$ only of the NFRs. The high rate of falls despite the use of walking aids maybe due to the improper use of the walking aids, e.g., carrying the walking frame instead of using it for support (Bloem et al., 2004). Moreover, using walking aids for mobility might reduce the patient's attention, and subsequently lead to FOG and falls; performing a secondary task while walking was suggested to trigger FOG leading to frequent falls (Bloem et al., 2004). Within the FRs group, significant correlations were found between FOG and history of falling suggesting a close association between FOG and increased falls risk. Bloem et al. (2004) projected that the suddenness of FOG will lead to balance disturbance and predisposition to falls. Knowing that FOG is more common in crowded places, narrow spaces, and in time-restricted, stressful situations such as when the telephone or doorbell rings (Schaafsma et al., 2003), it is not surprising that FRs tend to have higher rates of falls and greater risk of balance disturbance. Moreover, in more advanced stages of PD, FOG can appear more frequently and be more prolonged, thereby severely limiting walking and creating higher risk of falls (Giladi et al., 2001a; Giladi et al., 2001b). In addition to the high prevalence of falls and the higher percentage of walking aids utilization in the FRs group, a moderate correlation was also found between NFOG-Q total scores and Q29 of the UPDRS-III, which investigates the gait disturbance and need for assistance while walking in FRs. Gait disturbance and high risk of falls seem to be the main trigger for assistance-seeking behaviour in FRs. More than two thirds of the FRs needed carer assistance, mainly for mobility and transfer related activities, compared to less than half of the NFRs requiring such assistance.

The results of the study show a weak correlation between the NFOG-Q and the UPDRS-III scores $(\mathrm{R}=0.24)$, providing further evidence that FOG is an independent motor symptom of PD, caused by a paroxysmal pathology that is different from that responsible for bradykinesia, rigidity or postural instability (Bartels et al., 2003). On the other hand, moderate correlation $(\mathrm{R}=0.5)$ was found between NFOG-Q and the daily 
dopamine dose. This is in line with previous studies that investigated the relationship between FOG and Levodopa treatment; total Levodopa daily dose and duration of Levodopa treatment were strongly associated with the presence of FOG (Giladi et al., 2001a; Lamberti et al., 1997). FOG tends to be mild, short lasting, and with minimal impact on gait at the early stages of the disease prior to the introduction of Levodopa, while at the advanced stages of PD, FOG is much more disabling, lasts longer, and frequently leads to falls (Giladi et al., 2001a). This confirms previous reports that disease progression and Levodopa treatment are major contributing factors for FOG development (Giladi et al., 2001a; Lamberti et al., 1997).

In previous investigations, higher $\mathrm{H} \& \mathrm{Y}$ stages were associated with the occurrence of FOG (Giladi et al., 2001a; Lamberti et al., 1997). In the current study, moderate correlation were observed between the NFOG-Q and the H\&Y scores $(\mathrm{R}=0.6)$ suggesting a high association between the FOG and the disease progression as indicated by the H\&Y stage. It was proposed that the strong relationship between FOG and H\&Y stage is not just due to the effect of the progression of the PD in general but specifically with the development of postural reflexes abnormalities in stage three of the H\&Y scale (Giladi et al., 2001a).

The findings of this study suggests the presence of a vicious cycle among subjects with PD, where FOG constitutes a major risk factor for increased frequency of falls among FRs as well as increased fear of falling and reduced confidence while walking, which in turn increases the tendency towards higher reliance on carers' assistance and more utilization of walking aids. It also suggests that FOG-related gait disturbance, increased fear of falling, and reduced independency will all lead to reduced mobility and functioning, with subsequent weakness, osteoporosis, pressure sores, and cardiovascular deconditioning, which might raise the risk of injuries, fractures, and further postural instability secondary to osteoporosis and weakness, and eventually will result in poorer quality of life, more need for hospitalization, and nursing home admission. An effective way of addressing such cycle might be to ensure proper use of the walking aids among FRs and provision of appropriate training on the use of such aids in order to minimise the risk of falls related to the improper use of the walking aids. One of the limitations of the study is that it did not distinguish between the "on" and "off" states of medication. Further studies should take into account testing the subjects during the "on" and "off" states.

\section{CONCLUSION}

The results of the current study confirm that FOG might be an independent motor symptom of PD that has a different underlying pathology than those of other PD symptoms. It also suggests that disease duration, medication, and disease progression might be influential predictors of the presence of FOG. Comparing FRs and NFRs revealed that FOG is associated with greater gait disturbance and higher risk and frequency of falls, subsequently leading to more walking aids utilization and more need for carers to assist with mobility and transfers. Interventions are needed to address falls and FOG in the PD population to ensure maintained mobility, independence and quality of life for subjects as well as preserved resources for the health organizations.

\section{PERSPECTIVE}

The FOG-related gait disturbance and risk of falls have devastating impact on the patients' lives, as, in most cases, it will lead to injuries, fractures, reduced functioning, depression, social isolation, need for assistance, reduced independency and poor general physical and mental well-being. From research, clinical and policy perspectives, FOG and falls have recently received increasing recognition for their clinical impact on the patients and the financial burden on the health care systems. Most health care systems strive now to achieve the balance between 
high quality heath services and cost-effective health care systems. Interventions looking into addressing the problem of FOG in subjects with PD will serve to reduce risk of falls, improve mobility, independence and quality of life, and reduce health and social care services utilization and hospital admission.

\section{REFERENCES}

Bartels, A.L., Balash, Y., Gurevich, T., Schaafsma, J.D., Hausdorff, J.M., \& Giladi, N. (2003). Relationship between freezing of gait (FOG) and other features of Parkinson's: FOG is not correlated with bradykinesia. Journal of Clinical Neuroscience, 10(5), 584-588. doi:10.1016/S0967-5868(03)00192-9

Bloem, B.R., Hausdorff, J.M., Visser, J.E. \& Giladi, N. (2004). Falls and freezing of gait in Parkinson's disease: A review of two interconnected, episodic phenomena. Movement Disorders 19(8), 871-884. DOI: 10.1002/mds.20115

Camicioli, R., Oken, B.S., Sexton, G., Kaye, J.A., \& Nutt, J.G. (1998). Verbal fluency task affects gait in Parkinson's disease with motor freezing. Journal of Geriatric Psychiatry and Neurology, 11, 181-185.

Cubo, E., Leurgans, S., \& Goetz, C.G. (2004). Short-term and practice effects of metronome pacing in Parkinson's disease patients with gait freezing while in the 'on' state: randomized single blind evaluation. Parkinsonism and Related Disorders, 10, 507-510. doi:10.1016/j.parkreldis.2004.05.001

Davis, J.T., Lyons, K.E., \& Pahwa, R. (2006). Freezing of gait after bilateral subthalamic nucleus stimulation for Parkinson's disease. Clinical Neurology and Neurosurgery, 108, 461-464. doi:10.1016/j.clineuro.2005.07.008

Deuschl, G., Schade-Brittinger, C., Krack, P., $\&$ the German Parkinsonism study group. (2006). A randomized trial of deep-brain stimulation for Parkinson's disease. The New England Journal of Medicine, 355(9), 896-908.
Fahn, S., \& Elton, R.L. (1987). Unified Parkinson's Disease Rating Scale. In: Fahn, S., Marsden, C.D., Goldstein, M., \& Calne, D.B. (eds) Recent Developments in Parkinson's Disease. Macmillan, New York, 153-163.

Fahn, S. (1995). The freezing phenomenon in Parkinsonism. In: Fahn, S., Hallett, M., Lüders, H.O., \& Marsden, C.D. (eds). Negative motor phenomena. Advances in Neurology. Philadelphia: LippincottRaven, 67, 53-63.

Giladi, N., Treves, T.A., Simon, E.S., Shabtai, H., Orlov, Y., Kandinov, B., Paleacu, D., \& Korczyn, A.D. (2001a). Freezing of gait in patients with advanced Parkinson's disease. Journal of Neural Transmission, 108, 53-61. doi: 10.1007/s007020170096

Giladi, N., McDermott, M.P., Fahn, S., Przedborski, S., Jankovic, J., Stern, M., Tanner, C. \& the Parkinson Study Group (2001b). Freezing of gait in PD: Prospective assessment in the DATATOP cohort.

Neurology, 56, 1713-1721.

Giladi, N., Shabtai, H., Rozenberg, E., \& Shabtai, E. (2001c). Gait festination in Parkinson's disease. Parkinsonism \& Related Disorders, 7(2), 135-138. doi:10.1016/S1353-8020(00)00030-4

Giladi, N., \& Hausdorff, J.M. (2006). The role of mental function in the pathogenesis of freezing of gait in Parkinson's disease. Journal of the Neurological Sciences, 248 (1-2), 173-176.

doi:10.1016/j.jns.2006.05.015

Gray, P., \& Hildebrand, K. (2000). Fall risk factors in Parkinson's disease. Journal of Neuroscience Nursing, 32, 222-228.

Hausdorff, J.M., Schaafsma, J.D., Balash, Y., Bartels, A.L., Gurevich, T., \& Giladi, N. (2003). Impaired regulation of stride variability in Parkinson's disease subjects with freezing of gait. Experimental Brain Research, 149, 187-194. doi: 10.1007/s00221-002-1354-8

Hely, M.A., Morris, J.G., Traficante, R., Reid, W.G., O'Sullivan, D.J., \& Williamson, P.M. (1999). The Sydney multicentre study of Parkinson's disease: Progression and mortality at 10 years. Journal of Neurology, 
Neurosurgery, and Psychiatry, 67, 300-307. doi:10.1136/jnnp.67.3.300

Hoehn, M.M., \& Yahr, M.D. (1967).

Parkinsonism: Onset, progression and mortality. Neurology, 17(5), 427-442.

Hughes, A.J., Daniel, S.E., Kilford, L., \& Lees, A.J. (1992). Accuracy of clinical diagnosis of idiopathic Parkinson's disease: a clinico-pathological study of 100 cases. Journal of Neurology, Neurosurgery, and Psychiatry, 55, 181-184. doi:10.1136/jnnp.55.3.181

Lamberti, P., Armenise, S., Castaldo, V., de Mari, M., Iliceto, G., Tronci, P., \& Serlenga, L. (1997). Freezing gait in Parkinson's disease. European Neurology, 38(4), 297301. doi: 10.1159/000113398

Latt, M.D., Menz, H.B., Fung, V.S., \& Lord, S.R. (2009). Acceleration patterns of the head and pelvis during gait in older people with Parkinson's disease: A comparison of fallers and non-fallers. Journals of Gerontology Series A: Biological Sciences and Medical Sciences, 64A, 700-706. doi:10.1093/gerona/glp009

Nieuwboer, A., Rochester, L., Herman, T., Vandenberghe, W., Ehab Emil, G.,
Thomaes, T., \& Giladi, N. (2009).

Reliability of the new freezing of gait questionnaire: Agreement between patients with Parkinson's disease and their carers.

Gait \& Posture, 30, 459-463.

doi:10.1016/j.gaitpost.2009.07.108

Schaafsma, J.D., Balash, Y., Gurevich, T., Bartels, A.L., Hausdorff, J.M., \& Giladi, N. (2003). Characterization of freezing of gait subtypes and the response of each to levodopa in Parkinson's disease. European Journal of Neurology, 10, 391-398. doi: 10.1046/j.1468-1331.2003.00611.

The author would like to thank Professor Alice Nieuwboer, Faculty of Movement and Rehabilitation Sciences, Katholieke Universiteit Leuven, Belgium for her continuous support and for many helpful discussions and comments throughout the study.

Corresponding author's e-mail address: ehab.georgy@hchc.nhs.uk

\section{STARRES GANGBILD BEI PARKINSON-KRANKHEIT: EINFLUSS AUF DAS STURZRISIKO, GEBRAUCH VON GEHHILFEN UND HILFESUCHVERHALTEN}

(Resümee)

Ein starres Gangbild (Freezing of Gait - FOG) ist eines der am meisten störenden Symptome im fortgeschrittenen Stadium der Parkinson-Krankheit (Parkinson Disease - PD), das auch stark mit wiederkehrenden Stürzen und reduzierter funktionaler Unabhängigkeit verbunden ist. Die Absicht dieser Studie war es, den Einfluss dieses starren Gangs auf die Mobilität hinsichtlich Stürzen, Gehhilfen und Hilfesuchverhalten zu untersuchen, indem Betroffene mit (,freezers“ - FRs) und ohne starres Gangbild („non-freezers“ - NFRs) verglichen wurden. Klinische und demografische Daten, einschließlich Erkennung, Dauer, Phase und Charakteristiken der Krankheit, Medikation, Sturzchronik, Gebrauch von Gehhilfen sowie auftretendes Hilfesuchverhalten, wurden von 102 Probanden mit PD von drei medizinischen Zentren in Belgien, Israel und UK gesammelt. Eine Verbindung zwischen FOG und anderen Krankheitscharakteristiken, der Medikation, Stürzen und dem Bedarf an Betreuungshilfe wurde untersucht. Der Vergleich zwischen FRs und NFRs zeigte signifikante Unterschiede in der Vorgeschichte hinsichtlich Stürzen, dem Gebrauch von Gehhilfen und dem Bedarf an Betreuungshilfe. Mehr als die Hälfte der FRs berichteten von früheren Stürzen 
und von Bedarf an Gehhilfen gegenüber nur $20 \%$ in der Gruppe der NFRs. Ein Teufelskreis scheint zu existieren unter den Probanden mit PD, die ein starres Gangbild (FOG) aufweisen. Die Starrheit des Ganges induziert ein erhöhtes Risiko und höhere Häufigkeit von Stürzen sowie auch vermehrte Sturzangst, die wiederum die Tendenz zu stärkerem Vertrauen auf Betreuung und mehr Gebrauch von Gehilfen ansteigen lässt.

SCHLÜSSELWÖRTER: Parkinson-Krankheit, starres Gangbild, Stürze; Gehhilfen, Assistenz.

\section{“FREEZING" LORS DE LA MARCHE CHEZ DES PERSONNES ATTEINTES DE LA MALADIE DE PARKINSON : IMPACT SUR LES RISQUES DE CHUTE, L'UTILISATION D'AIDE A LA MARCHE ET COMPORTEMENT DE RECHERCHE D'ASSISTANCE}

(Résumé)

Le «freezing » durant la marche est un des symptômes les plus perturbants lors du stade avancé de la maladie de Parkinson qui est fortement corrélé avec des risques de chute et une réduction de l'indépendance fonctionnelle. L'objectif de cette étude était de déterminer l'impact du « freezing » lors de la marche sur les risques de chute, l'utilisation d'aide à la marche et le comportement de recherche d'assistance en comparant des sujets atteints de freezing (FR) et d'autres non atteints de freezing (NFR). Des données cliniques et démographiques ont été collectées auprès de 102 patients atteints de la maladie de Parkinson provenant de centres médicaux Belges, Israélien et Anglais. Ces données incluaient la durée de la maladie, le stade et les caractéristiques, la cognition, la prise de médicaments, l'historique des chutes, l'utilisation d'aide à la marche and le comportement de recherche d'assistance. L'association entre le freezing lors de la marche et les autres caractéristiques de la maladie, la prise de médicaments, les chutes, les aides à la marche and le besoin d'assistance ont été étudiés. La comparaison des deux groupes, FR et NFR, a révélé une différence significative de l'historique des chutes, de l'utilisation d'aide à la marche et du besoin d'assistance. Plus de la moitié des sujets FR ont rapporté des chutes et l'utilisation d'aide à la marche contre $20 \%$ pour les sujets NFR. Un cercle vicieux existe chez les personnes atteintes de la maladie de Parkinson et qui sont sujets au freezing durant la marche. Freezing durant la marche augmente le risque et la fréquence de chute ainsi que la peur de tomber, ce qui par conséquent augmente la recherche d'assistance et l'utilisation d'aide à la marche.

MOTS CLEFS: Maladie de Parkinson; freezing de marche; chutes; aide à la marche; assistance. 